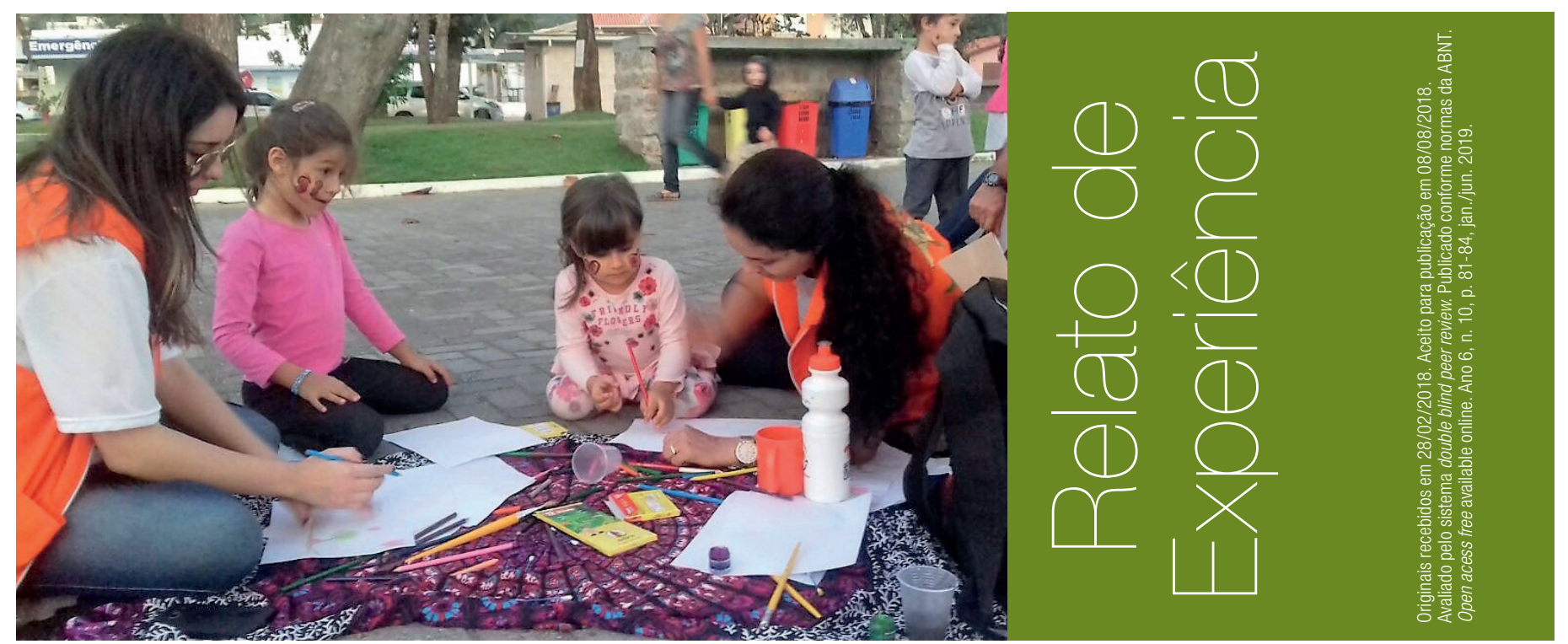

\title{
Extensão na prática: a interação institucional com a sociedade
}

\author{
Victória Luiza Schelbauer de Lima - victoriaschelbauer@gmail.com \\ Jerusa Fumagalli Schaf Nunes - jerusafumagalli@hotmail.com²
}

\section{RESUMO}

0 presente relato de experiência visa apresentar as ações do Núcleo Extensionista Rondon (NER), que vem possibilitando 0 intercâmbio dos acadêmicos e a inserção da universidade em diferentes áreas de conhecimento, abrangendo nesta operação a Secretaria de Desenvolvimento Regional (SDR) de Braço do Norte, Criciúma, Laguna e Tubarão. 0 Instituto Federal de Santa Catarina (IFSC) é parceiro institucional nessa iniciativa, que busca o desenvolvimento regional, interdisciplinaridade e interação entre a universidade e a sociedade.

\section{PALAVRAS-CHAVE}

Núcleo Extensionista. Intercâmbio. Interdisciplinaridade. Interação.

\section{ABSTRACT}

The present experience report aims to present Rondon Extension Nucleus (NER - UDESC) actions, which has made possible the exchange of academics and the insertion of the university in different areas of knowledge, covering the regional area of Braço do Norte, Criciúma, Laguna and Tubarão. The IFSC is an institutional partner in this initiative, which seeks regional development, interdisciplinarity and interaction between the university and society.

\footnotetext{
1 Técnica em Agroindústria (IFSC), graduada em Tecnologia de Alimentos (IFSC), pós-graduanda em Tecnologia de Bebidas Alcoólicas Pública (IFSC).

2 Enfermeira. Especialista em Ginecologia e Obstetrícia. Docente do Centro de Educação Profissional - CEDUP - Chapecó
} 


\section{KEYWORDS}

Extensionist Core. Exchange. Interdisciplinarity. Interaction.

\section{Relato de experiência}

Através da extensão universitária é possível repassar à sociedade os conhecimentos educativos, culturais e científicos adquiridos na sala de aula, viabilizando uma interação transformadora entre a instituição e a comunidade. 0 Instituto Federal de Santa Catarina (IFSC), em parceria com a Universidade do Estado de Santa Catarina (Udesc), atuaram com a finalidade de selecionar bolsistas para participarem do Núcleo Extensionista Rondon.

0 Núcleo Extensionista Rondon (NER) da Udesc vem possibilitando o intercâmbio entre as instituições e universidades e tem o objetivo de promover a integração social e interdisciplinar das instituições de ensino superior, envolvendo estudantes de forma voluntária em busca de soluções que contribuam para o desenvolvimento sustentável de comunidades, ampliando 0 bem-estar da população.

Busca-se, assim, a garantia da interdisciplinaridade, da interação entre a universidade e a sociedade e da qualidade e do impacto das ações de Extensão no âmbito da Udesc, reforçando a missão da universidade diante da realidade social.

A diversidade das áreas de origem dos acadêmicos possibilitou o fortalecimento das noções de interdisciplinaridade para o desenvolvimento das oficinas realizadas no município, contando com as áreas de enfermagem, educação física, física, matemática, fisioterapia, medicina, história, tecnologia em alimentos, engenharia do petróleo, engenharia agronômica e sanitária.

A operação aqui relatada foi realizada no município de Garopaba, litoral Sul de Santa Catarina, onde os alunos tiveram a oportunidade de colocar em prática todos os conhecimentos adquiridos no decorrer de sua graduação, aliando teoria e prática.

Nesta edição do projeto, mais de 300 acadêmicos, dos quais 15 do IFSC, participaram de atividades em 22 municípios na área de abrangência das agências de Desenvolvimento Regional de Braço do Norte, Criciúma, Laguna e Tubarão, entre 12 e 22 de julho.

Figura 1: Gincana com alunos da escola municipal de Garopaba.

Fonte: Núcleo Extensionista Rondon

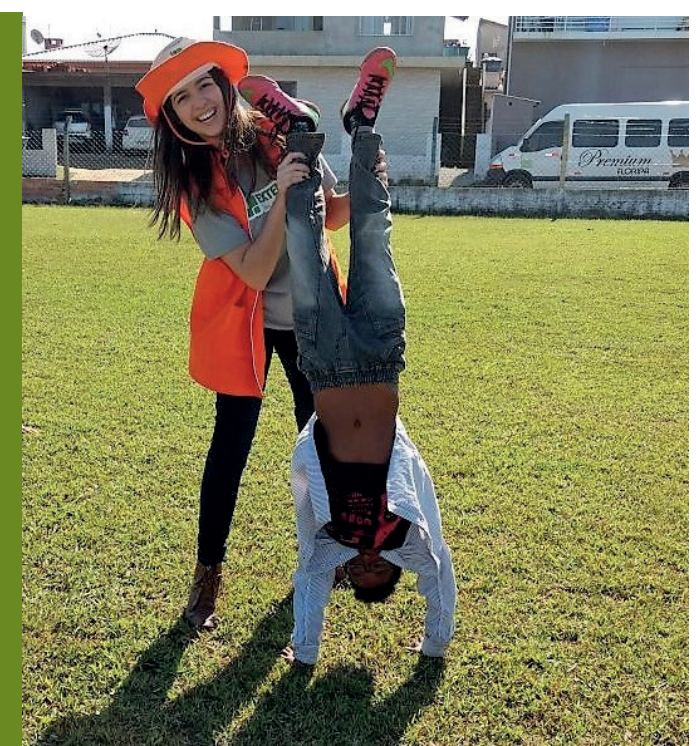

A primeira gincana foi realizada em uma escola municipal (Figura 1) em que os alunos do ensino fundamental puderam participar das brincadeiras com muita diversão. As gincanas eram constituídas por professores da própria escola, em parceria com os alunos extensionistas; nelas foram utilizadas bolas de futebol para brincar e fazer jogos com as crianças, além da corrida no saco entre três turmas, entre outras brincadeiras. A interação com as crianças foi de suma importância para conhecer o meio em que elas vivem e a sua realidade na escola. 
Realizamos atividades recreativas na praça principal de Garopaba, ocorrendo a interação entre a população com o Núcleo Extensionista Rondon. A oficina foi realizada em um domingo, visto que as famílias gostavam de passear na praça com as crianças. Foram levados papéis em branco, tintas guache e pincéis para alcançar a interação entre os extensionistas e a comunidade.

Além das atividades recreativas, houve o "abraço grátis" para quem quisesse participar, criando assim um laço afetivo com a comunidade. As pessoas que participavam, perguntavam sobre 0 Núcleo Extensionista, parabenizando os acadêmicos pela ação voluntária.

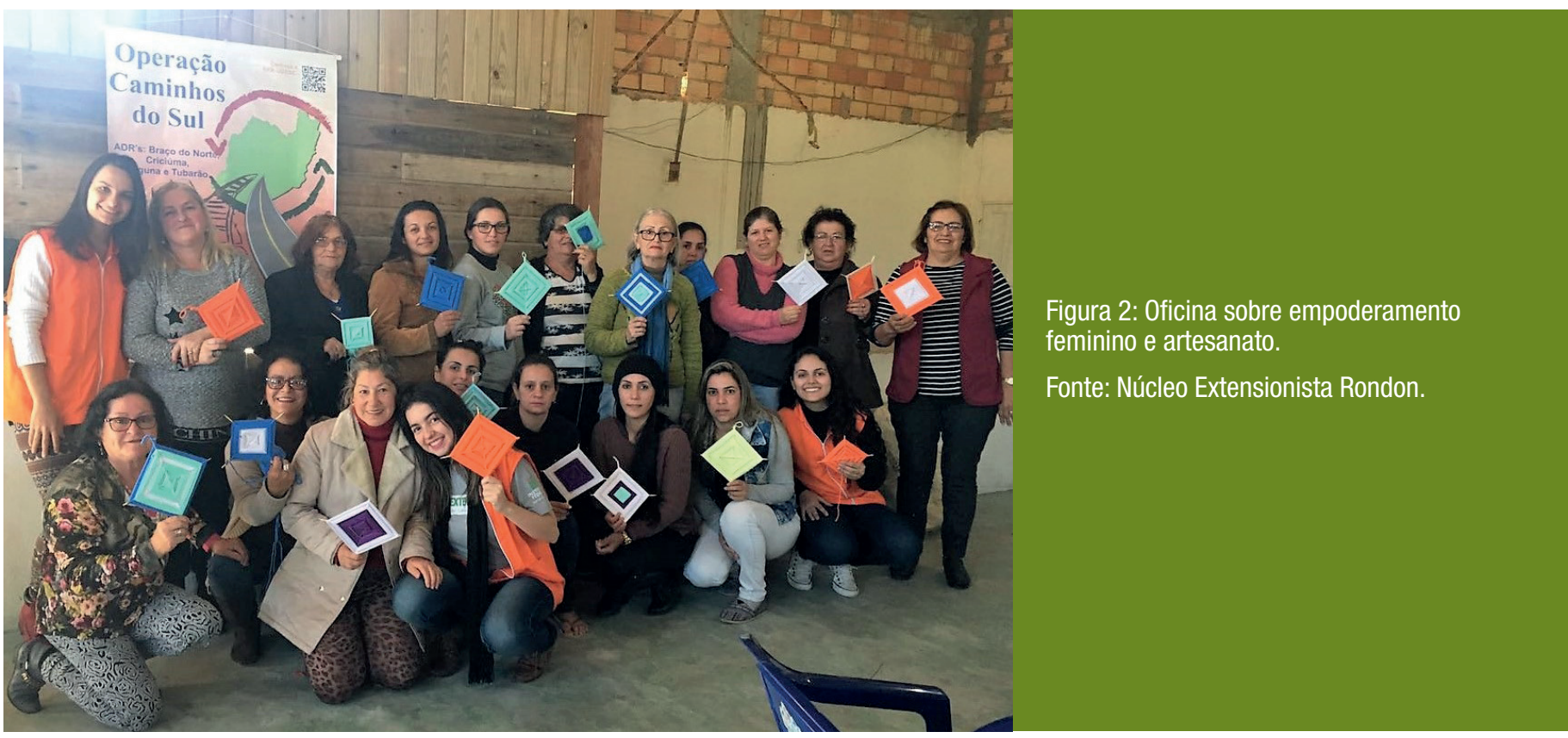

Como mostra a Figura 2, foi realizada uma oficina sobre empoderamento feminino com um grupo de mulheres pertencentes a uma comunidade deslocada de Garopaba. Foi realizado um debate sobre a cultura machista, violência contra a mulher e sobre os direitos das mulheres. Enquanto ocorria o debate, foram desenvolvidas mandalas como forma de aprendizagem sobre artesanato, causando uma participação mais ativa do público alvo. Observou-se que a maioria das mulheres sofriam com a desigualdade de gênero em relação a serviços domésticos, pois de acordo com os relatos elas eram responsáveis por todos os afazeres, enquanto seus maridos apenas praticavam seus hobbies, como ver jogo de futebol ou sair com os amigos.

No final da oficina, foi realizada uma dinâmica para questionar as mulheres presentes sobre 0 que elas pensavam de si próprias. Foi colocado um espelho dentro de uma bolsa fechada, e cada mulher que abria a bolsa via o espelho e apontava o que estava vendo, destacando a sua aparência, o seu estado emocional, como esta pessoa se sentia em casa, diante da família, do marido e como poderia melhorar diante da situação.

Empoderar mulheres e promover a equidade de gênero em todas as atividades sociais e da economia são garantias para o efetivo fortalecimento das economias, o impulsionamento dos negócios, a melhoria da qualidade de vida de mulheres, homens e crianças e para 0 desenvolvimento sustentável (ONU, 2018). 


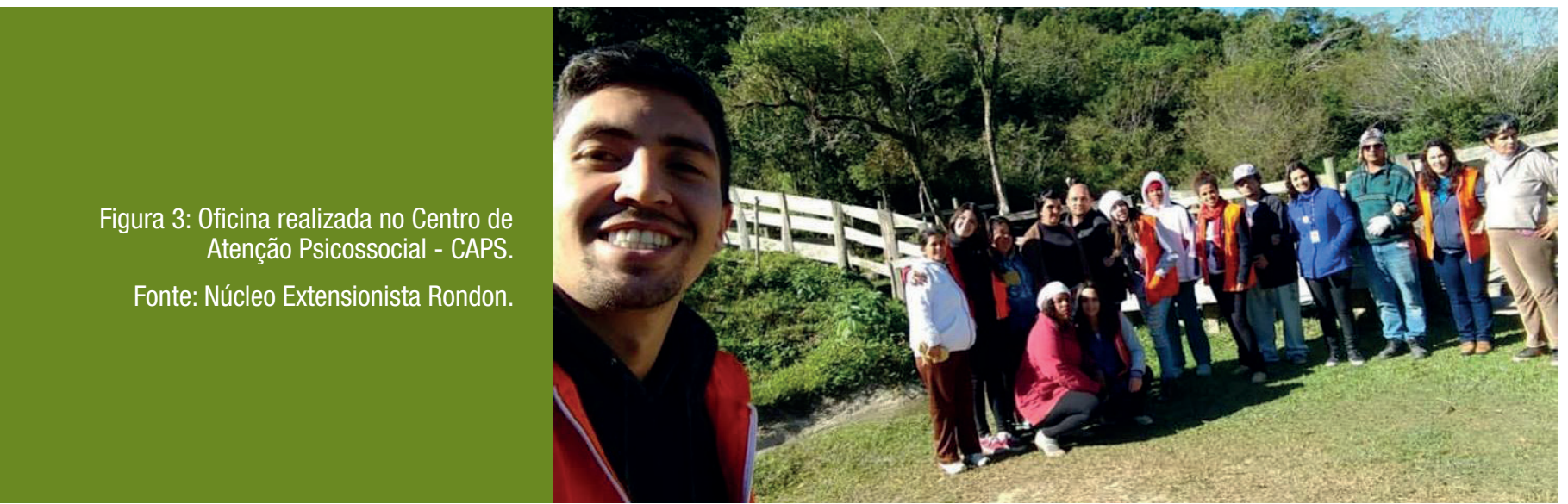

A atenção psicossocial prestada pelo Centro de Atenção Psicossocial (Caps) pressupõe um acolhimento dos sujeitos com sofrimento psíquico e transtorno mental, um conjunto de ações que visam à substituição da lógica manicomial como base de sustentação teórica para o cuidado em saúde mental e do modo asilar como paradigma das práticas dominantes (OLIVEIRA, 2009).

0 grupo ficou no período matutino e vespertino no Caps, acompanhando os pacientes, conhecendo as suas histórias de vida. Um passeio no quarteirão ajudou a promover a afinidade entre 0 grupo. Foram realizadas brincadeiras, danças e desenho. Houve muita interação entre os alunos e 0 grupo.

Atualmente a universidade tem se pautado no ensino, pesquisa e extensão, uma vez que desde 0 final do século XIX deixa de focar apenas o ensino como sua função por excelência e passa a desenvolver também a pesquisa.

A Operação Caminhos do Sul bateu o recorde de mais de 47 mil pessoas atendidas em atividades de extensão. No total, foram 1.250 oficinas realizadas e 340 extensionistas participantes. Houve ações gratuitas nas oito áreas da extensão universitária: educação; saúde; meio ambiente; direitos humanos e justiça; cultura; comunicação; trabalho; e tecnologia e produção.

A extensão pode ser notada como uma resposta da universidade para a sociedade que a financia; ação com foco em todas comunidades catarinense e/ou brasileira; ação da academia para as comunidades e a ação de compartilhamento entre o saber científico, produzido nesta academia, e o do senso comum presente na comunidade.

\section{Referências}

NÚCLEO EXTENSIONISTA RONDON. In: UDESC. Disponível em: http://www.udesc.br/ nucleorondon. Acesso em: 25 de fev. 2018.

OLIVEIRA, W. F. Éticas em conflito: reforma psiquiátrica e lógica manicomial. Caderno Brasileiro de Saúde Mental, Florianópolis, v. 1, n. 2, p. 48-61, out./dez. 2009. Disponível em: http://periodicos.incubadora. ufsc.br/index.php/cbsm/article/view/1126. Acesso em: 27 fev. 2018.

ONU MULHERES BRASIL. In: ONU. Disponível em: http://www.onumulheres.org.br/referencias/ principios-de-empoderamento-das-mulheres/. Acesso em: 25 fev. 2018 